\title{
An Analysis of the Factors Affecting Individual Perception about the Difficulty in Accessing Government Services in China
}

\author{
Ling $\mathrm{Xu}^{1}$, Xiyang Feng ${ }^{2}$ \\ ${ }^{1}$ School of Public Administration Guangzhou University, Guangzhou, China, xuling_1@126.com \\ ${ }^{2}$ School of Public Administration Guangzhou University, Guangzhou, China, fengxiyang_1@126.com
}

\begin{abstract}
Recently, the reform of administrative examination and approval system has greatly enhanced the quality and efficiency of public service in China. However, with the rapid increase of public demands, the public service reform has to transform from the physical reaction stage to the chemical integration phase. In other words, we must change the traditional reforming measures, such as setting up the unified service hall, improving serving attitude, simplifying the approval process, monitoring the approval efficiency, to the holistic government construction stage that sets up an integrated platform for multiple public services by using the information system. In this study, we conduct a public opinion survey in Guangzhou, and aim to figure out the factors that influence individual perception about the difficulty in accessing public services. Based on the development process of service reforms conducted by the Guangzhou government, we propose three key factors affecting individual perception about the difficulty in accessing public services, including government service quality, government service items, and government service methods. The results provide some support to our argument that the government service items and methods exert significant influence on individual perception about the difficulty in accessing public services. Based on our empirical result, we offer some policy suggestions for the local government.
\end{abstract}

KEYWORDS: Difficulty in accessing government services, Government service quality, Government service items, Government service methods, Reform of administrative examination and approval system

\section{The presentation of questions}

"It is hard to ask for the leaders of the government to deal with our personal affairs", which is the evaluation and opinion of the people to the government. In recent years, the Chinese government has taken a series of initiatives and approaches to solve the problem faced by the public people that is hard for them to deal with personal affairs to the government. It has even tried to improve the efficiency of the government in handling affairs for the people through round after round of reform of the administrative examination and approval system. The government has also issued a request to strengthen the reform of government service to promote the effective realization of the "last kilometer" mission of government service recently.

On November 27, 2015, the General Office of the State Council issued the Notice on Simplifying and Optimizing the Flow of Public Service to Facilitate the Grassroots to Handle Business and Entrepreneurship, and issued a prescription for solving the difficulties in handling affairs from three aspects. The first is "cataloguing," which needs to make a comprehensive review of public service matters and make the list of catalogues public to people. The contents of the catalogue mainly include two aspects, which include those that serve the needs of entrepreneurship and innovation, and those closely related to the daily production and life of the masses. The second is "reducing the amount of proof," by the way of resolutely cutting off all kinds of pointless proof and complicated procedures. The third is making it have "simple flow," to minimize the number of work links.

Based on the practice and the latest exploration of the government service reform in Guangzhou, combined with the public opinion survey on the degree of difficulty from Guangzhou people to the government, this paper tries to find out the main factors that affect the degree of difficulty from the public to the government, and finally puts forward some policy advice for the Guangzhou Municipal People's Government. 


\section{The basis of practice}

Stage 1: it is the "centralized examination and approval" period. Through the way of the establishment of the unified administrative examination and approval of the administrative service center (lobby) of "three concentrations" and "three in place," it can solve the problems caused by the fact that people have to run multiple functional departments in different offices to do business with the government.

Stage 2: it is the "smiling government affairs" period. Through improving the attitude of government service and strengthening its service consciousness, it can solve the problem that people have difficulty in getting close to government.

Stage 3: it is the "efficient government affairs" period. Through simplifying the approval process and monitoring the approval effectiveness, it can solve the problem that people have difficulty in getting close to government. In the administrative examination and approval, the key to restrict the effectiveness of administrative examination and approval is the unscientific process of administrative examination and approval, the complicated items of administrative examination and approval, and the time-consuming and laborious problems of administrative examination and approval.

Stage 4: it is the "integrated government affairs" period. By using the powerful information system and big data, we can construct a plural and integrated public service platform to solve the problem that people have difficulty in getting close to government.

\section{The hypothesis of research}

\subsection{The possible factors that affect the degree of difficulty for people to get close to the government}

As mentioned earlier, based on the practice and exploration of the reform of the administrative examination and approval system in China, the government will focus on the reform in every stage in order to solve the problem that people have difficulty in getting close to government. As there is few research on the factors influencing the degree of difficulty from the public in order to get close to the government, we can only start from the practice of government reform and try to generalize the potential factors that affect the people to get close to the government. It is believed that there are three main aspects as follows:

\subsubsection{The quality of government service}

The service quality of government affairs mainly includes three sub-items, such as the attitude of government service, the effectiveness of government service and the process of government affairs service. The attitude of government service is based on the important goal of "smiling government affairs" in the reform of administrative examination and approval. It focuses on solving the problems of poor service attitude and weak service consciousness of government service staff when people come to the government to handle affairs. The effectiveness of administrative service is the important mission of the stage of "centralized examination and approval" and "efficient government affairs" in the reform of administrative examination and approval system. By streamlining the administrative examination and approval items, optimizing the administrative examination and approval process, and realizing the two-track efficient operation of "parallel examination and approval" and "tandem examination and approval", it can reduce the complicated examination and approval procedures encountered by the public to deal with the affairs with the government, and avoid the problem that they need to run many departments, which is time-consuming and painstaking similar to the "long march."

\subsubsection{The items of government service}

For the reform stage of "efficient government affairs" in the administrative examination and approval system, while it focuses on optimizing the service flow of government affairs, supervising the examination and approval effectiveness, streamlining and devolving the examination and approval items, it also emphasizes the important matters that the people have difficulty in handling affairs with the government, and carries on the process combing and reconstructing with strong pertinence. 


\subsubsection{The mode of government service}

According to the Holistic Government theory (Perri 6, 1997), the mode of government is an important factor in the public service. The "integrated government affairs" stage of the reform of the administrative examination and approval system emphasizes the adoption of a powerful government information system, as well as the establishment of a plural and integrated public service platform. Professor $\mathrm{Zhu}$ figure out that the government management is changing from the new public management to the overall governance (Zhu 2008), and some scholars even consider that the Holistic Government is the new trend of governance (Kou 2012). The traditional government affairs service hall will be connected with the government online service hall, the government service multifunctional integrated card, the government hotline, the grid officer, the government affairs service entrusting agent, Government WeChat (Weibo), it is also the period which transforms the reform of government affairs service from physical reaction period to chemical synthesis.

\subsection{The presentation of research hypothesis}

In this paper, it mainly discusses the relationship between the quality of government service, the affairs of government service, the mode of government service and the degree of difficulty from the public to get close to the government. Based on the above theoretical support and the practical basis of the reform of the administrative examination and approval system in China, we put forward the following three hypotheses in this study:

Hypothesis one: The more concern to the affairs made by the government reform, the less difficult it will be for the public to get close to the government to deal with the matter.

Hypothesis two: The higher the quality of government services provided by the government to the public, the less difficult it will be for the public to get close to the government to deal with the matter.

Hypothesis three: The more people use convenient government services, the less difficult it will be for the public to get close to the government to deal with the matter.

We hope to fully understand the influencing factors that affect the degree of difficulty for the public to get close to the government to deal with the matter through verifying the above three hypotheses in this study.

\section{Research materials, conceptual measurement and research methods}

\subsection{Research material}

In order to fully understand the degree of difficulty for the Guangzhou population in accessing the government, we went to Guangzhou government affairs service center in October 2014 to conduct a questionnaire survey to the people who came to deal with affairs. The questionnaire survey was conducted by 64 students from Class 3, School of Public Administration, Guangzhou University. They went to Guangzhou Government Affairs Service Center, Guangzhou Haizhu District Government Affairs Service Center, Guangzhou Liwan District Government Affairs Service Center, Guangzhou Yuexiu District Government Affairs Service Center, Guangzhou Panyu District Government Affairs Service Center, Guangzhou Baiyun District Government Affairs Service Center respectively to make the survey.

The object of the survey was the people who had come to the Government Affairs Service Center to deal with affairs. A total of 640 questionnaires were distributed and 625 valid questionnaires were returned. The reason why we chose these six government affairs service centers in Guangzhou to conduct the survey was that we mainly considered their representativeness, which had both old and new urban areas. At the same time, we controlled the number of questionnaires distributed as a whole. There were 130 questionnaires (20.8\%), 131 (21.0\%), 101 (16.2\%), $106(17.0 \%), 79(12.6 \%)$ and 78 $(12.5 \%)$ in the six government affairs service centers respectively in order to ensure the randomness and representativeness of the samples as far as possible. The duration of the survey was two weeks. And the questionnaire mainly revolved around the three influencing factors of government affairs service matters, government affairs service mode and government affairs service quality. 


\subsection{Conceptual measurement}

In this survey, we mainly made the measurement from three factors, which include government affairs service matters, government affairs service mode and government affairs service quality in order to analyze their influence on the degree of difficulty from the public in accessing to the government. At the same time, five variables were added, such as sex, age, occupation, residence location and education level.

\subsubsection{Dependent variable: The degree of difficulty for people to get close to government to deal with their personal affairs}

In the regression analysis model, we take the degree of difficulty from the public in accessing to the government as a dependent variable, and specifically divide it into five levels, which include not difficult, less difficult, general/good, much difficult, very difficult, in turn, 1 for not difficult, 2 for less difficult, 3 for average/good, 4 for much difficult, 5 for very difficult. The higher the numerical value, the greater the difficulty coefficient; conversely, the lower the numerical value, the smaller the difficulty coefficient.

\subsubsection{Independent variables}

\subsubsection{On the measurement of matters of government affairs service}

According to the current division standard of Guangzhou government affairs service items, we divide the government affairs service items into two main categories, which include individual affairs and enterprise affairs. And we make individual affairs as the baseline group for regression statistical analysis.

\subsubsection{On the measurement of government affairs service quality}

We divide the service quality of government affairs into three dimensions, which include service attitude, service flow and service timeliness. The survey was conducted mainly by asking the interviewees, "what do you think is the main reason for the difficulties in accessing the government"? Among them, we mainly listed 10 reasons for the interviewees to choose from. In data processing, we made a statistical analysis of the reasons that each interviewee thought was the most important. The 10 reasons included: A. There are many examination and approval links, which need to run more than one department to deal with affairs. B. It takes a long time for the examination and approval. C. Windows staff have low level to deal with affairs. D. It needs long time to queue. E. The staff have subjective arbitrariness. F. One needs to look for someone he or she knows to help them. G. The staff have poor service attitude. H. One needs to give them benefit. I. It needs the material that are multiple and repeated. J. Others.

In the course of data analysis, we classified the ten reasons into three variables: the quality of government affairs service personnel, the process of government affairs service and the effectiveness of government affairs service. Among them, the attitude of government affairs service includes six reasons of $\mathrm{C}, \mathrm{E}, \mathrm{G}, \mathrm{H}, \mathrm{F}, \mathrm{J}$, the government affairs service process includes two reasons of $\mathrm{A}$, I, and the government affairs service effectiveness includes two reasons of $\mathrm{B}, \mathrm{D}$. We take the attitude of government affairs service as the benchmark group, and put the process of government affairs service and the effectiveness of government affairs service as variables into the regression model for statistical analysis.

\subsubsection{On the measurement of the way of government affairs service}

In combination with the more commonly used ways of government affairs service that have been developed, we have listed six options: A. Lobby processing. B. Online processing. C. Electronic equipment self-service processing. D. Entrusting agent E. Government hotline. F. Other means of processing. Then, by asking the interviewee, "what is the way you used to do business with the government," we can make the ranking from more to less, the first assignment was 6 , followed by the value of $5,4,3,2,1$, and for options that are not selected, the assignment is 0 . In other words, the more people use a certain form of government service, the higher the score is. We think that online processing and government hotline are more convenient than the other four options. Therefore, the 
more often people use these two methods, the less difficult it is for the common people in accessing the government.

\subsection{Research methods}

In the study, the main research method we use is multivariate linear regression. It is hoped that through this statistical research method, we can understand the influencing factors of the degree of difficulty for the public in accessing government services. In the construction of model, dependent variables are the degree of difficulty for the public in accessing government services; and the independent variables are further subdivided according to the three influential factors, such as the service quality of government affairs, the matters of government affairs service and the mode of government affairs service. Based on the development stage of Guangzhou government affairs service reform, we divide the government affairs service into two variables, which include individual affairs and enterprise affairs, and we take individual affairs as the benchmark group. The service quality of government affairs is divided into three variables, such as service attitude, service flow and service effectiveness, and the service attitude is made as the benchmark group. The way of government affairs service is divided into six variables, which includes hall processing, online processing, electronic equipment self-help processing, entrusted agent, government hotline and other service modes.

To probe into the influence of the quality of government affairs service, the matters of government affairs and the way of government affairs service on the degree of difficulty for people in accessing the government services, we put the variables of the influencing factors of the above three dimensions into the regression model together with the control variables of age, education level, sex and household registration. In the treatment of control variables, we divide the sex into two groups, male and female, with women as the benchmark group. The age of the interviewees is divided into six age groups, one that is under 20 years old, 20-30 years old, 31-40 years old, 51-60 years old and over 60 years old, and the age under 20 years old is made as the benchmark group. As for the education level, the sample is divided into two categories, which includes below high school, and over university, as the education level below high school is made as the benchmark group. For the location of the household registration, the respondents are divided into two categories, which include being born in Guangzhou or not being born in Guangzhou, and the not being born in Guangzhou is taken as the benchmark group. The models constructed in this paper are as follows:

The degree of difficulty for people in accessing government service $=\alpha+\beta_{1}$ (Enterprise matters)+ $\beta_{2}$ (Service flow) $+\beta_{3}$ (Service effectiveness) $+\beta_{4}$ (Hall processing)) $+\beta_{5}$ (Online processing) $+\beta_{6}$ (Electronic equipment self-help processing) $+\beta_{7}$ (Entrusting agent) + $\beta_{8}$ (Government hotline) $+\beta_{9}$ (Other service modes) $+\beta_{10}$ (Male) $+\beta_{11}$ (Age 20-30) + $\beta_{12}\left(\right.$ Age 31-40) $+\beta_{13}$ (Age 41-5) $+\beta_{14}$ (Age 51-60) $+\beta_{15}$ (Age over 61) $+\beta_{16}$ (University or over) $+\beta_{17}$ (Born in Guangzho)

\section{The analysis and interpretation of data}

The table 1 shows the results of regression analysis. As described in the table, enterprise affairs, online processing, government hotline and other services modes are all statistically significant. Among them, the people dealing with enterprise affairs are 0.229 units less difficult than those who handle individual affairs. Secondly, as for the service modes of the public in accessing the government, online processing, government hotline and others all have statistical significance. Among them, the people who use online processing more often think that the difficulty degree in accessing government service is lower (with correlation coefficient is -0.089), the people who use the government hotline more often think that the difficulty degree in accessing government service is higher (with correlation coefficient is 0.090).

On hypothesis one: The more concern to the affairs made by the government reform, the less difficult it will be for the public to get close to the government to deal with the matter. On hypothesis two: The higher the quality of government services provided by the government to the public, the less difficult it will be for the public to get close to the government to deal with the matter. On hypothesis 
three: The more people use convenient government services, the less difficult it will be for the public to get close to the government to deal with the matter.

Table 1 Regression model of factors influencing people's difficulty in getting close to government to deal with matter

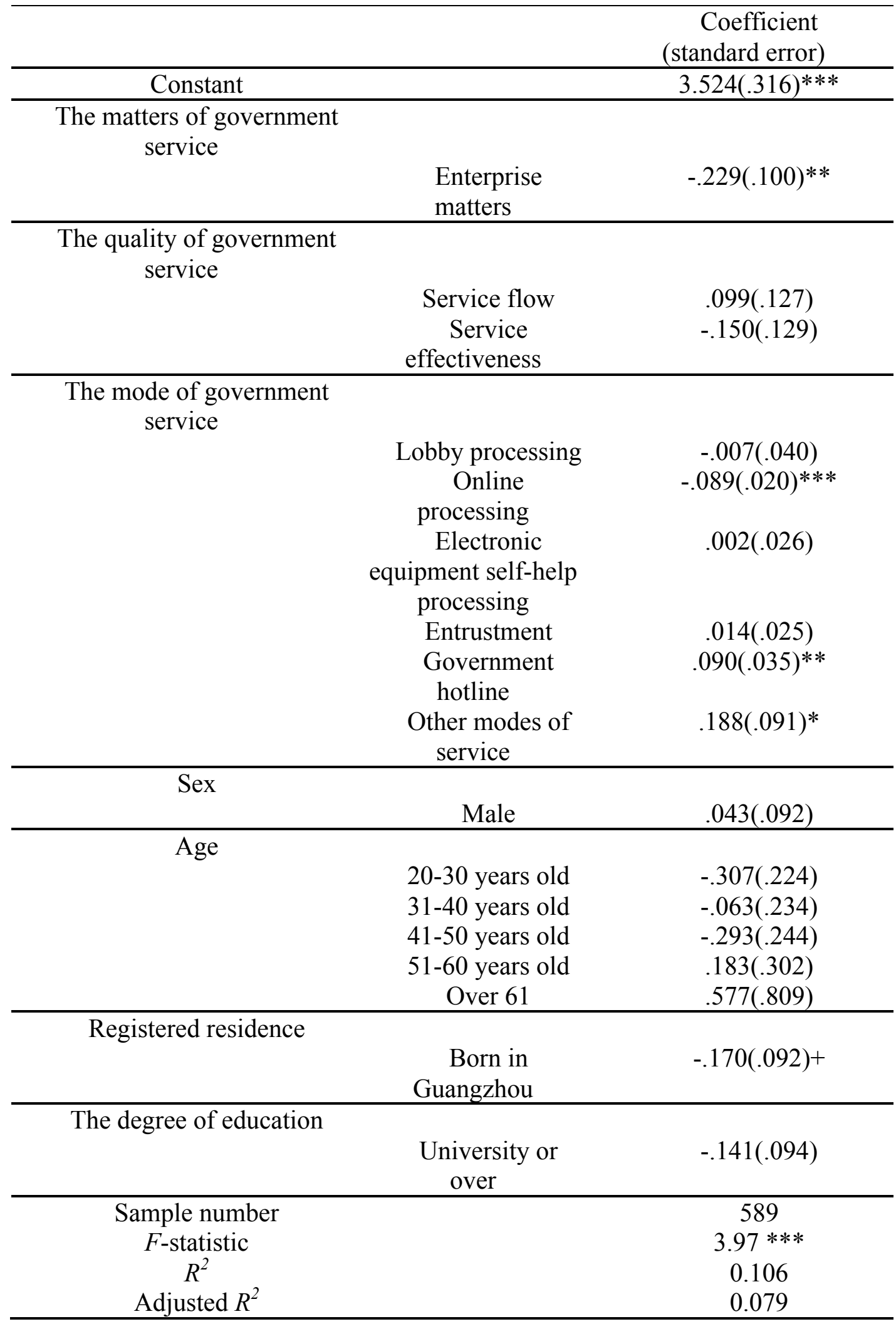

Explanation:***: $p<0.001 ; * *: p<0.01 ; *: p<0.05 ;+: p<0.10$. 
In conclusion, through statistical analysis of regression model, we successfully validate hypothesis one; negate hypothesis two; partially validate hypothesis three.

\section{Conclusion}

Based on the above findings, we can get to the following conclusions:

First, the more attention paid by the government on the matters that need to solve, the lower the degree of difficulty will be for people to get close to the government to deal with things. This proves that, as long as a matter that attracts sufficient attention from the government and then proceeds with relevant reform measures, it can effectively reduce the degree of difficulty for people in accessing government service. However, how to effectively determine the next stage of the reform of the administrative examination and approval system, it should be locked in those specific items to carry out highly targeted reforms, by diagnosing the most difficult issues through public opinion polls, and then it can start a new round of reform of the administrative examination and approval system around these issues.

Second, the reform of government service attitude, service flow and service effectiveness have no significant influence on the degree of difficulty for people in getting close to the government. Therefore, the reform of administrative examination and approval system needs to enter the stage of transformation and upgrading. On the basis of the current achievements of government affairs reform, the reform of government service attitude optimization, service flow sorting as well as the examination and approval streamlining has been relatively accomplished to the utmost. In the next stage, it is difficult to achieve the breakthrough results in these traditional dimensions of administrative examination and approval reform. In order to achieve new breakthroughs and progress, the reform of contemporary Chinese government affairs must find another way.

Third, in the ways of government affairs service, it has no influence on the difficulty for people to get close to government service for the ways hall processing, entrusting agent, and electronic equipment self-help processing, while online processing, the government hotline service mode is related to the degree of the difficulty for people to get close to government service. Among them, the construction of the web office has a big response, and the voice of the public is high, so we can further strengthen the construction of the online lobby and the electronic government affairs. However, data from the government hotline, which is a form of government service, shows that the more people use this kind of service, the more difficult it is for them to get close to government service.

\section{References}

Perri 6. 1997. Holistic Government. UK, London: Demos.

Kou, Dan. 2012. „Holistic Governance: A New Trend of Government Governance.” Journal of Northeastern University (Social Science) 3: 230-233.

Zhu, Qianwei. 2008. „From New Public Management to Holistic Governance.” Chinese Public Administration 10: $52-58$. 